\title{
Development of a Cancer Related Patient Empowerment Scale Using the Polytomous Rasch Measurement Model
}

\author{
Caroline Elizabeth Bulsara ${ }^{1} \&$ Irene Styles ${ }^{2}$ \\ ${ }^{1}$ The Brightwater Care Group, The University of Western Australia, Perth, Australia \\ ${ }^{2}$ Pearson Psychometrics Laboratory, The University of Western Australia, Perth, Australia \\ Correspondence: Dr Caroline Bulsara, Adjunct Research Fellow, Inaugural Director of the Brightwater Research \\ Centre, the University of Western Australia, Perth, Australia. E-mail: caroline.bulsara@brightwatergroup.com
}

\author{
Received: December 12, 2012 Accepted: January 7, 2013 Online Published: January 9, 2013 \\ doi:10.5539/cco.v2n1p87 URL: http://dx.doi.org/10.5539/cco.v2n1p87
}

There is no known conflict of interest for either author of this manuscript

\begin{abstract}
Aims and objectives: A scale to measure empowerment amongst cancer patients was developed in order to understand and quantify empowerment amongst cancer patients. Background: Within the field of cancer research, understanding the ways in which cancer patients gain control over their illness can be an important factor in helping patients reduce anxiety and maintain a reasonable quality of life. Design: The Patient Empowerment Scale was developed from a set of markers identified from the literature on empowerment and self-efficacy and from interviews with patients. Methods: The Polytomous Rasch Measurement Model was selected as the most appropriate means of examining the psychometric properties of the scale items, and of investigating how cancer patient respondents interacted with each statement. Results: Items from the initial 28 -item scale were refined using the results from the Rasch analysis to form the final 15-item scale. The Person Separation Index of 0.78 indicated an acceptable degree of reliability. Conclusion: The results indicate the scale has acceptable psychometric properties which may be enhanced by the development of more intense items to better measure patients with high levels of empowerment and thereby increase the reliability of their measures.
\end{abstract}

Keywords: patient empowerment, patient involvement, cancer, Rasch Model, oncology

\section{Introduction}

Empowerment is recognized as an important means of cancer patients maintaining a certain amount of control over their experience of their illness (Arora, 2003). However, empowerment is an ill-defined concept that is often described in terms of a person's mechanism for coping without a definitive conceptualization of the characteristics of empowerment. Furthermore, there are no instruments which measure the presumably different levels of empowerment in individuals with cancer (Rissel, 1994).

The study aimed to identify enabling elements of empowerment common to patients being treated for cancer and from those, to construct a valid, reliable instrument to measure patient empowerment. We postulated the development of an empowerment scale would facilitate understanding of what empowerment is, and the ways it is achieved by cancer patients. A study of the components of empowerment could give credibility to the belief that empowerment is an important aspect of patients' coping strategies (Molinari, Ahern, \& Hendryx, 1998; Zaza, Sellick, \& Hillier, 2005). A scale to measure empowerment could be used to identify persons in need of help in becoming empowered, as well as the most efficacious strategies. This paper reports the development of such a scale and identifies the markers for empowerment used to develop the scale.

\section{Background}

In attempting to regain control over an illness, previous work has shown that empowerment operates as a more proactive strategy than 'coping' (Bulsara, \& Styles, 2006; Bulsara, Chan, \& Styles, 2007). A patient who 'copes' may accept information provided by a doctor but is not motivated to seek information and options beyond this. Therefore, the power residing in the information provider - in this case, the doctor - remains absolute. In contrast, an 'empowered patient' proactively asks questions and seeks solutions for themselves to manage their illness 
(Perkins et al., 1995). Perkins \& Zimmerman (1995) see empowerment as“...a construct that links individual strengths and competencies, natural helping systems and proactive behaviours." This concept relates to other concepts such as self-efficacy and self-management. Previous work has shown quality of life to be improved by increased involvement in decision-making regarding management of illness, and the use of strategies to enable patients feel they were in control. These two aspects seem to be fundamental to empowerment (Bulsara et al., 2004; Wu, Chin, Haase, \& Chen, 2009). Thus empowerment incorporates the way patients seek to optimise outcomes of treatment (Taylor, Litcheman, \& Wood, 1984; Golant, Altman, \& Martin, 2003). The study was based on the premise that empowerment cannot be adequately measured by other quality of life scales such as the coping scale (COPE) (Carver, Scheier, \& Weintraub, 1989), decision-making preferences scales (Degner, 1998), or the Mental Adjustment to Cancer and the Hospital Anxiety and Depression Scale (Watson et al., 1998; Zigmond \& Snaith, 1983). Constructs on which these scales are based differently from the concept of empowerment particularly in relation to the interaction the patient seeks from others (Carver et al., 1989).

Empowerment may be regarded as an attitude which some patients hold by being more involved in the treatment of their illness. Triandis (1971) notes that an 'attitude' is inferred from what a person says, accompanied by how he/she feels about a stimulus. In this context, the stimuli are strategies identified by patients such as use of resources, information, and support. Patients' attitudes to those stimuli will be demonstrated in terms of level of agreement with a particular belief about the stimuli. Attitudes can be expressed cognitively as statements (eg that the health professional has confidence in the patient's ability to cope) and behaviourally as overt actions (eg adapting pace of lifestyle or attending a support group).

Since empowerment is not directly observable it must be defined operationally through the development of a measure to quantify this construct. Patients experience setbacks throughout their illness, particularly in regard to cancer where the liminality of the illness is evident (Little, Jordens, Paul, Montgomery, \& Philipson, 1998). However, levels of empowerment are envisaged as transcending specific points in time during the illness. Thus markers for inclusion in the scale are aspects in which it is conceivable for patients to remain in control of their situation despite setbacks. This study sought to address the lack of instruments to assess empowerment amongst cancer patients by developing a scale focusing on areas of control affecting diagnosis and treatment outcomes, and the strategies by which patients may proactively manage their illness. Measures obtained may be used to assess patients' ability to adapt to their illness and draw upon the resources most relevant to their needs, in the expectation this will lead to an improved quality of life.

A project titled The Haematology Shared Care Model conducted at a metropolitan teaching hospital in Perth, Western Australia (Ward, Hardwick, \& Joske, 2000), aimed to promote proactive patient engagement throughout the illness trajectory. Patients were encouraged to use particular strategies to gain control of aspects of their cancer treatment (eg managing side effects), in the expectation that these behaviours would lead to a sense of control (empowerment) (Ward et al., 2000).

The empowerment scale was developed in conjunction with this study based on interview data from patients and material in the literature described above. This resulted in the identification of markers for empowerment such as use of resources, involvement in decision-making, relationships with GPs and other health professionals, perceived usefulness of the patient, use of complementary therapies, and spiritual beliefs. The Rasch measurement model, described next, was used to examine the psychometric properties of the scale.

\section{Methodology}

\subsection{The Rasch Measurement Model}

A construct or latent trait such as empowerment cannot be observed directly but rather through manifested behaviours (Ryan, 1983) that can be represented by statements for each of which respondents indicate their degree of agreement or disagreement. Statements are constructed to represent more or less of the construct. The data obtained from administration of a set of such statements to a sample of persons can be examined to establish the psychometric properties of the scale. The polytomous Rasch measurement model (Andrich \& Styles, 2009) was selected as the means of examining properties (validity and reliability) of the scale items. The Rasch measurement model was deemed most appropriate because it is the only measurement model which satisfies the principles of invariance of measurement (Andrich, 1988; Bond \& Fox, 2001; Wright \& Stone, 1979; Rasch, 1980). Two consequences of invariance follow. Firstly, as outlined by Andrich \& Styles (2004), when responses to items of a scale fit the Rasch model, person and item measures will be on a linear continuum. Secondly, measures will be invariant across groups for which fit is verified. If this is not the case, analysis can identify anomalies in the data which may be causing misfit. Identifying anomalies can lead to a better understanding of the construct. From the perspective of the Rasch paradigm, if data do not fit the model, it is the data that are 
subjected to scrutiny to understand why there is misfit. This is the opposite of the view taken in traditional test theory and in the two and three-parameter logistic models where the goal is to find the model that best fits the data and where there is misfit, to alter the model to accommodate the data (Andrich, \& Styles, 2004; Andrich, 2004). These properties indicate that scores may legitimately be subjected to mathematical operations and measures may be compared directly across persons or items - clearly vital characteristics for a measurement scale. The markers/items which form, in this case, the Patient Empowerment Scale, should remain consistent in intensity relative to one another across groups of patients and circumstances (prognosis and illness trajectory), to be able to compare and interpret levels of the property in different patients or in the same person over time. Thus, the Rasch Model was selected as the most appropriate means of examining the psychometric properties of the scale items such as validity and reliability, and of investigating how respondents were interacting with (responding to) each statement.

As noted, the Rasch model requires that responses to the items fit the model in order to obtain invariant measures. Items for a final scale following initial analyses are thus discarded or modified based on several criteria as follows:

1. How well they fit the model

2. How close in location they were to each other

3. How close in meaning they were.

4. Whether residual correlations between pairs of items were high (indicating dependency between pairs of items)

There are four steps to be taken in a basic Rasch analysis of a scale. These are now described further for the results of the final patient empowerment scale.

A concept central to measurement is that of unidimensionality. From the perspective of the Rasch paradigm, unidimensionality implies that empowerment is measurable as a single construct at the level of scale of its intended use, and in relative isolation from other constructs which may influence it (Andrich, 1988). Although empowerment may be seen as a complex construct involving a variety of different aspects, our hypothesis is that for the purpose of identifying general levels of empowerment, these aspects can be regarded as elements of a single variable. It is an empirical question, testable through the Rasch model, whether this is the case (Andrich, \& Styles, 2004). For purposes of investigating specific areas of empowerment, it may be that a profile of measures on subsets of items from the full scale may be more useful than a single measure - this procedure would assess empowerment at a different (finer) level of scale for a different purpose.

In summary, if the items that operationalise a construct fit the Rasch model, then the items form a single linear continuum in which the order of items is invariant across all relevant populations and the measures of the degree to which persons display the trait or construct are invariant across all subsets of items (Rasch, 1980). The purpose of using the Rasch measurement model to help validate the Patient Empowerment Scale was, therefore, to establish whether the latent trait or construct of 'empowerment' had been successfully operationalised as a single variable.

\subsection{Patient Population Demographics}

Development of the scale occurred in two stages: firstly, a pilot study was conducted with a small group of patients $(\mathrm{n}=101)$, after which the scale was modified; secondly, a final study using the modified scale was conducted with another small group of patients $(n=101)$ from a second location as detailed below. These procedures are described, followed by the details of data analyses. Patient data is shown in Table 1 below. The main focus of this stage of the development of the scale sought a broad sample of patients across a number of demographic variables with the intention that the scale be as generic in terms of the individual empowerment concept as possible. 
Table 1. Patient demographics $(\mathrm{N}=202)$

\begin{tabular}{|c|c|c|c|}
\hline & Group $1(n=101)$ & Group $2(n=101)$ & Total (N) \\
\hline \multicolumn{4}{|l|}{ Mean age in years (grouped) } \\
\hline Mean age by group & $51-60 \mathrm{yrs}$ & $51-60 \mathrm{yrs}$ & $51-60 \mathrm{yrs}$ \\
\hline \multicolumn{4}{|l|}{ Gender (\%) } \\
\hline Male & 41.0 & 43.0 & 42.0 \\
\hline Female & 55.4 & 53.0 & 54.4 \\
\hline Not specified & 3.6 & 4.0 & 3.6 \\
\hline \multicolumn{4}{|l|}{ Marital status (\%) } \\
\hline Married & 64.4 & 65.4 & 64.9 \\
\hline Divorced & 13.9 & 13.9 & 13.9 \\
\hline Widowed & 7.9 & 7.9 & 7.9 \\
\hline Never married & 10.9 & 11.9 & 11.4 \\
\hline \multicolumn{4}{|l|}{ Type of cancer } \\
\hline Breast & 20.8 & 53.5 & 37.1 \\
\hline $\begin{array}{l}\text { Haematological (e.g } \\
\text { Lymphoma/myeloma) }\end{array}$ & 15.8 & 0 & 7.9 \\
\hline Sarcoma & 2.0 & 0 & 0.9 \\
\hline Colon & 2.8 & & 1.5 \\
\hline Prostate & 2.8 & & 1.5 \\
\hline Lung & 5.0 & & 2.5 \\
\hline Ovarian & 6.0 & & 3.0 \\
\hline Other (e.g. liver, bladder) & 15.0 & & 7.4 \\
\hline Melanoma & 4.0 & 0 & 1.9 \\
\hline Not specified & 25.8 & 46.5 & 36.1 \\
\hline
\end{tabular}

\subsection{Initial Pilot Study}

Twenty-eight items were generated from a review of literature and the main themes from twelve Haematology Clinic Shared Care cancer patient interviews pertaining to management of their illness (Bulsara et al., 2004). The extensive literature review was carried out in the area of motivation and self-efficacy to identify markers for decision-making preferences and patient empowerment to guide the development of interview questions. Secondly, patients willing to be interviewed were identified by their specialist and Haematology Care Centre nursing staff through their involvement in the trial Shared Care program taking place within the Haematology Department. All patients had expressed a strong coping ability in regard to the management of their illness regardless of prognosis. In-depth interviews were initially conducted with twelve of the Shared Care patients regarding their use of coping strategies and the positive effects of being more fully included in the management of their illness. A set of these strategies were identified by both patients and the researcher as markers for coping with the illness and whether the strategies also positively contributed to a greater sense of empowerment. All twelve patients were contacted again to request a second interview. This second interview specifically related to issues of empowerment and patients' use of coping strategies in the management of their illness. Seven of the original twelve Shared Care patients completed a second interview. Common themes from all interviews (including the initial pilot project patient interviews with the twelve patients) and the literature relating to coping with cancer were collated. The fourteen themes thus identified were then operationalised into pairs of statements corresponding to each theme. As noted in the previous section, items were generated from the total of twenty semi-structured interviews along with the extensive literature review.

The statements covered the concepts of access to relevant and timely information about their illness, social support networks, open and positive communication between health professionals themselves and with the patient, decision-making involvement, and adjustment to acceptance of their illness. Other topics of importance included use of complementary therapies, religion and/or spirituality and feeling useful in terms of paid/unpaid 
employment. The statements were then reviewed by a haematological cancer specialist, a researcher and breast cancer survivor and three academics with extensive experience in Rasch measurement and scale construction.

\subsection{Identifying Concepts for Inclusion in the Empowerment Scale}

Strategies for achieving empowerment amongst patients can be implemented on several levels. However, most importantly, these strategies attempt to provide patients with the knowledge, skills and the "belief in (sense of) self" necessary to take control of their lives once more following the diagnosis of cancer. It is by using these concepts that an empowerment scale measuring various aspects regarding perceived loss of control was developed. Communication appeared to be a key factor in the development of patient empowerment and this theme recurred many times throughout the interviews. Furthermore, patients indicated many levels of involvement in their treatment and care. Areas of control which came to light during the afore mentioned Shared Care pilot study were the importance of access to information, communication with and between health professionals and patients, choice of treatment location and involvement where possible in type of treatment. Items addressing these areas were incorporated into the scale as a means of registering levels of empowerment as perceived by the patient. It was evident from the qualitative component of the study that employing specific strategies such as support of family and friends, informed involvement in the decision making process and access to relevant resources enables patients to cope better and to feel that they have some measure of control over their illness. Being informed and involved in the process of treating and managing their cancer enables patients to feel more in control. A further review of relevant literature regarding decision-making preferences and issues of loss of control and empowerment amongst cancer patients ensured that concepts developed from the Shared Care project concurred with current and previous literature. As explained previously, transcripts of the interviews with Shared Care patients were reviewed in order to ascertain aspects of their own empowerment experience. Themes were then noted and developed into a set of statements which made up the initial Patient Empowerment Scale. Statements were developed from the perspective of the cancer patient in relation to their illness. Main themes initially identified were patient control of illness, patient choice of treatment location (in relation to the Shared Care model), patient information, support from others (non medical), feeling useful, spirituality, use of complementary therapies and acceptance of the illness. These themes were developed into items, comprising 14 strategies identified by patients and researcher serving as markers for not simply 'coping' but contributing to a greater sense of empowerment over a patient's situation. Items covered aspects of access to relevant, timely information, social support networks, open, positive communication between health professionals and patients, decision-making involvement, and adjustment to acceptance of illness. Other topics included use of complementary therapies, spirituality and feeling useful. To establish the face validity, items were reviewed by a haematological cancer specialist, researcher and breast cancer survivor, and three academics experienced in Rasch measurement and scale construction. 
Table 2. Strategies from which statements are constructed

\begin{tabular}{|c|c|}
\hline Type of strategy & Definition / marker for presence of strategy \\
\hline \multirow[t]{2}{*}{ Resources } & Capability of using resources to handle illness \\
\hline & Sufficient resources to handle illness \\
\hline \multirow[t]{2}{*}{ Information } & Sufficient information \\
\hline & Relevance of information \\
\hline \multirow[t]{2}{*}{ Involvement in decision making process } & Desire for involvement in decision making process \\
\hline & Capability to be involved in decision making process \\
\hline \multirow[t]{2}{*}{ Family support } & Availability of a supportive family \\
\hline & Patient need for the support of family \\
\hline \multirow[t]{2}{*}{ Support of friends } & Availability of supportive friends \\
\hline & Patient need for the support of friends \\
\hline \multirow[t]{2}{*}{ Relationship with GP } & Comfortable with GP \\
\hline & Familiarity with GP \\
\hline \multirow{2}{*}{$\begin{array}{l}\text { Patient perception of GP ability to } \\
\text { manage illness }\end{array}$} & Ability of GP to manage illness outside hospital \\
\hline & Confidence in local GP \\
\hline \multirow[t]{2}{*}{$\begin{array}{l}\text { Patient perception of health professionals } \\
\text { willingness to include them (DMP) }\end{array}$} & $\begin{array}{l}\text { Patient perception of health professionals' willingness to include } \\
\text { them in the decision making process }\end{array}$ \\
\hline & $\begin{array}{l}\text { Patient's capability of helping health professionals reach decisions } \\
\text { related to the illness. }\end{array}$ \\
\hline \multirow[t]{2}{*}{ Complementary therapies } & Use of complementary therapies \\
\hline & Complementary therapies help cope with illness \\
\hline \multirow[t]{2}{*}{ Spiritual beliefs } & Presence of spiritual beliefs \\
\hline & Spiritual beliefs help cope with illness \\
\hline \multirow[t]{2}{*}{ Acceptance and adaptability to illness } & Acceptance of need to change lifestyle \\
\hline & Ability to adapt lifestyle \\
\hline \multirow[t]{2}{*}{ Patient perceived usefulness to friends } & Friends' reliance on patient (usefulness/contribution) \\
\hline & Need by patient for friends' reliance \\
\hline \multirow[t]{2}{*}{ Patient perceived usefulness to family } & Family reliance on patient (usefulness / contribution) \\
\hline & Need by patient for family reliance \\
\hline \multirow[t]{2}{*}{ Paid employment } & Usefulness despite no longer being in paid employment \\
\hline & Usefulness due to paid employment \\
\hline
\end{tabular}

The Patient Empowerment Scale (PES) comprising 28 statements was administered to 101 cancer patients from the Haematology Care Centre, radiation oncology unit, and medical oncology clinic at a hospital in Perth, Western Australia. Each item was given a four-point rating scale (strongly agree, agree, disagree, and strongly disagree), scored 4, 3, 2 and 1, respectively. Patients were asked to select the response for each statement which most closely reflected their view. Statements were positively worded so increasing total scores were associated with increasing levels of empowerment. The Rasch Polytomous Model (RPM) for data with ordered categories (Andrich, 1978; Hagquist, 2001; Andrich et al., 2004) was used to examine the psychometric properties of the items. Evidence regarding the internal consistency and reliability of the PES items was gathered through analyses using the RUMM2020 software program (Andrich, Sheridan, \& Guanzhong, 2004). The overall goal was to achieve a valid and reliable scale of locally independent items with a wide range of locations covering as many different aspects of empowerment as possible. An additional goal was to reduce the number of items to render the questionnaire less arduous to complete. 


\subsection{The Final Patient Empowerment Scale (PES)}

Some items were deleted or modified based on the pilot study data analysis: the final Patient Empowerment Scale (PES) consisted of 15 items which included pilot study items that fitted the model, as well as a few pairs of items which were integrated with each other to form single items. Therefore, following the completion of the pilot analysis and in order to shorten the final version of the scale, decisions were taken to coalesce (integrate) some statements. These decisions were taken by reviewing items to see if they were close in location and also in meaning as noted in the methods section.

For example, of the two statements (PES12) 'I have spiritual beliefs' and (PES21) 'Spiritual beliefs help me cope with my illness', the latter fits the model better and seems to represent the variable better conceptually. Two further statements (PES09) 'I use complementary therapies' and the corresponding statement (PES24) 'Complementary therapies help me cope with my illness' also appeared close in meaning and in location on the continuum. The statement PES09 was discarded in favour of PES 24 ('Complementary therapies help me cope with my illness') which tells us more about the patient's attitude towards complementary therapies. Further, the statements relating to friends and family and employment / feeling useful are also located close together in the continuum (see below) in Table 3.

Table 3. Coalesced statements from initial analyses

\begin{tabular}{lll}
\hline Statement & Location & SE \\
\hline I have spiritual beliefs & 0.377 & 0.2 \\
Spiritual beliefs help me cope with my illness & 0.507 & 0.13 \\
I use complementary therapies & 0.874 & 0.211 \\
Complementary therapies help me cope with my illness & 1.234 & 0.147 \\
I want my family to continue to rely on me & 0.79 & 0.203 \\
I want my friends to continue to rely on me & 0.621 & 0.217 \\
My family still rely on me & 0.713 & 0.191 \\
My friends still rely on me & 1.069 & 0.221 \\
I still feel useful because I am in paid employment & 1.02 & 0.244 \\
I still feel useful ( no longer in paid employment) & -0.08 & 0.248 \\
I need the support of my family & -1.065 & 0.213 \\
I need the support of my friends & -0.31 & 0.203 \\
\hline
\end{tabular}

Although originally intended to be administered to patients who had participated in the Shared Care trial, the number $(\mathrm{N}=101)$ was insufficient to validate the scale. Thus, another sample $(\mathrm{N}=101)$ of primarily adjuvant breast cancer patients from a second hospital completed the modified scale and the pilot and final study data were analysed together. This was justified because 9 of the 15 items were common to both initial and final versions, and using Differential Item Functioning analysis, it was possible to examine whether the two samples interpreted the items in a similar way. The study was approved by the Human Ethics Committee at two hospital sites and is in accordance with the 1964 Declaration of Helsinki.

\section{Results}

The results for the pilot study are summarised and only the final study is reported in detail.

\subsection{Pilot study}

Table 4 shows the item locations and fit for all 28 items. Three tests of item fit were used. These were namely the log residual test of fit, the item-trait interaction test of fit, and graphical inspection of the Item Characteristic Curves (ICCs). The log residual is the difference between actual and observed scores. The extent to which objectivity is achieved will depend upon the degree to which the data fit the Rasch Model. Fit statistics will show the person-item response inconsistencies that affect the measurement objectivity of persons and items. The item-trait interaction is represented as a chi square value calculated from a comparison of the observed values of each trait group (patients) response to the item in comparison with the expected value. This quantifies the size of 
the departure of the empirical item characteristic curve from its model values, so identifying the magnitude of the item-by-trait (item-by-empowerment level) interaction for this item. Thirdly, the inspection of Item Characteristic (Probability) Curves show the probabilities of responding in each category across the range of person locations and indicate graphically whether the ordering of the categories is as intended. Three items $(8,13$ and 22) showed some misfit on the item-trait interaction test of fit, and one item (28) had log (Fit) residual value of $>2.00$.

Table 4. Item locations and fit for all 28 items of the Patient Empowerment Scale

\begin{tabular}{|c|c|c|c|c|c|c|c|}
\hline Item & $\begin{array}{l}\text { Location on scale } \\
\text { continuum }\end{array}$ & SE & $\begin{array}{c}\text { Fit } \\
\text { Residual* }\end{array}$ & DIF & ChiSq*** & DF & Prob \\
\hline 6. My family are very supportive & -1.91 & 0.165 & 0.999 & 185.3 & 0.66 & 2 & 0.719 \\
\hline 8. I am capable of making decisions related to my illness. & -1.603 & 0.227 & -2.137 & 89.42 & 12.503 & 2 & 0.002 \\
\hline 4. I want to be involved in making decisions (illness) & -1.478 & 0.226 & -1.593 & 88.5 & 6.469 & 2 & 0.039 \\
\hline 18. My friends are always supportive & -1.204 & 0.154 & 0.405 & 179.77 & 3.54 & 2 & 0.170 \\
\hline 11. I need the support of my family & -1.065 & 0.213 & 1.011 & 85.74 & 2.878 & 2 & 0.237 \\
\hline 1. I am capable of handling my illness & -0.711 & 0.145 & -1.679 & 185.3 & 2.019 & 2 & 0.364 \\
\hline 7. I am comfortable with seeing my GP & -0.673 & 0.201 & 0.741 & 86.66 & 0.826 & 2 & 0.662 \\
\hline $\begin{array}{l}\text { 5. I am capable of helping health professionals reach } \\
\text { decisions about my illness }\end{array}$ & -0.632 & 0.147 & -0.876 & 184.38 & 0.641 & 2 & 0.726 \\
\hline 2. have sufficient resources to handle my illness & -0.586 & 0.22 & -1.006 & 83.89 & 3.645 & 2 & 0.162 \\
\hline 26. I need the support of my friends & -0.31 & 0.203 & 0.707 & 83.89 & 0.896 & 2 & 0.639 \\
\hline 10. The info that I have is relevant to my illness & -0.206 & 0.235 & -1.747 & 82.97 & 3.085 & 2 & 0.214 \\
\hline 15. I can adapt to the changes in my lifestyle & -0.141 & 0.178 & -1.364 & 177.93 & 5.382 & 2 & 0.068 \\
\hline 27. I feel useful (no longer paid employment) & -0.08 & 0.248 & 0.068 & 60.84 & 0.287 & 2 & 0.866 \\
\hline $\begin{array}{l}\text { 16. Health professionals are happy to include me in } \\
\text { decisions related to my illness }\end{array}$ & 0.103 & 0.153 & -1.118 & 170.55 & 2.29 & 2 & 0.318 \\
\hline 25. I have a lot of confidence in my local GP & 0.134 & 0.135 & 1.197 & 173.32 & 1.146 & 2 & 0.564 \\
\hline 3. I have all the info I need to manage my illness & 0.182 & 0.208 & -0.236 & 87.58 & 2.239 & 2 & 0.326 \\
\hline 12. I have spiritual beliefs & 0.377 & 0.2 & 0.841 & 66.38 & 1.835 & 2 & 0.400 \\
\hline 22. I accept that I have to change my lifestyle & 0.445 & 0.147 & 0.215 & 174.24 & 11.101 & 2 & 0.004 \\
\hline 21. My spiritual beliefs help me cope with my illness & 0.507 & 0.13 & 0.796 & 147.5 & 1.651 & 2 & 0.438 \\
\hline 20. I want my friends to continue to rely on me & 0.621 & 0.217 & -0.446 & 71.91 & 0.07 & 2 & 0.966 \\
\hline 14. My family still rely on me & 0.713 & 0.191 & 1.499 & 76.52 & 2.084 & 2 & 0.353 \\
\hline 17. I want my family to continue to rely on me & 0.79 & 0.203 & 0.542 & 72.83 & 1.696 & 2 & 0.428 \\
\hline 9. I use complementary therapies & 0.874 & 0.211 & -0.674 & 50.7 & 2.27 & 2 & 0.321 \\
\hline 19. I still feel useful because I am in paid employment & 1.02 & 0.244 & 0.749 & 37.8 & 1.004 & 2 & 0.605 \\
\hline 23. My friends still rely on me. & 1.069 & 0.221 & -0.693 & 74.67 & 0.258 & 2 & 0.879 \\
\hline 28. I know my GP really well. & 1.144 & 0.194 & 2.526 & 79.28 & 1.856 & 2 & 0.395 \\
\hline 24. Complementary therapies help me cope with my illness & 1.234 & 0.147 & 0.396 & 118.92 & 1.935 & 2 & 0.380 \\
\hline 13. My GP is able to manage my illness outside of hospital & 1.386 & 0.194 & 0.407 & 80.2 & 10.653 & 2 & 0.005 \\
\hline
\end{tabular}

*Difference between value observed and expected value - fit / log residual

**Item trait interaction test of fit 
Differential Item Functioning (DIF) analyses carried out according to three Site Locations within two teaching hospitals and were namely Haematology, Oncology and Radiation Oncology. In addition, the analyses were also performed with two gender groups, six age groups and marital status groups. However, these need to be interpreted cautiously due to small numbers in sub-classes. One item showed some DIF according to the Site Location (Item 16 - health professionals are happy to include me in decisions related to my illness) and one according to Marital status (Item 19 - I feel useful because I am still in paid employment). Clearly little DIF existed: at this stage in scale development no action was taken on these items.

Examination of inter-item residual correlations indicated 18 pairs of items showing some local dependence (> 0.33 cut point for correlation coefficients), but these tended to be randomly located and most did not involve particular sub-groups of items.

Items were targeted to the majority of persons in this sample though some persons with high levels of empowerment were not being measured as reliably as most people (no items were targeted at their levels).

\subsection{Final Patient Empowerment Scale (PES)}

Based on pilot study analyses, thirteen statements were coalesced or discarded, resulting in a final fifteen-item PES scale. Those close in location as described earlier in the manuscript were coalesced and the remaining items shown below were discarded as they did not fit the model well.

I have sufficient resources to handle my illness (e.g. support groups, talking to others outside of the medical profession).

(1) I am capable of making decisions related to my illness.

(2) I think my GP is able to manage my illness outside of hospital.

(3) I am comfortable with seeing my GP.

(4) The information that I have is relevant to managing my illness.

(5) I want to be involved in making decisions related to my illness.

(6) I know my GP very well.

The item trait chi square value is graphically represented as an indicator of item behaviour. The statement (2 above and shown in Figure1 below) "I am capable of making decisions relating to my illness." Shows that the cause of the misfit (in this case, over-discrimination) for the statement is uncertain (refer Figure 1). However, it is close in meaning to two other similar statements regarding decision making involvement. For these reasons, the statement was discarded in the final scale.

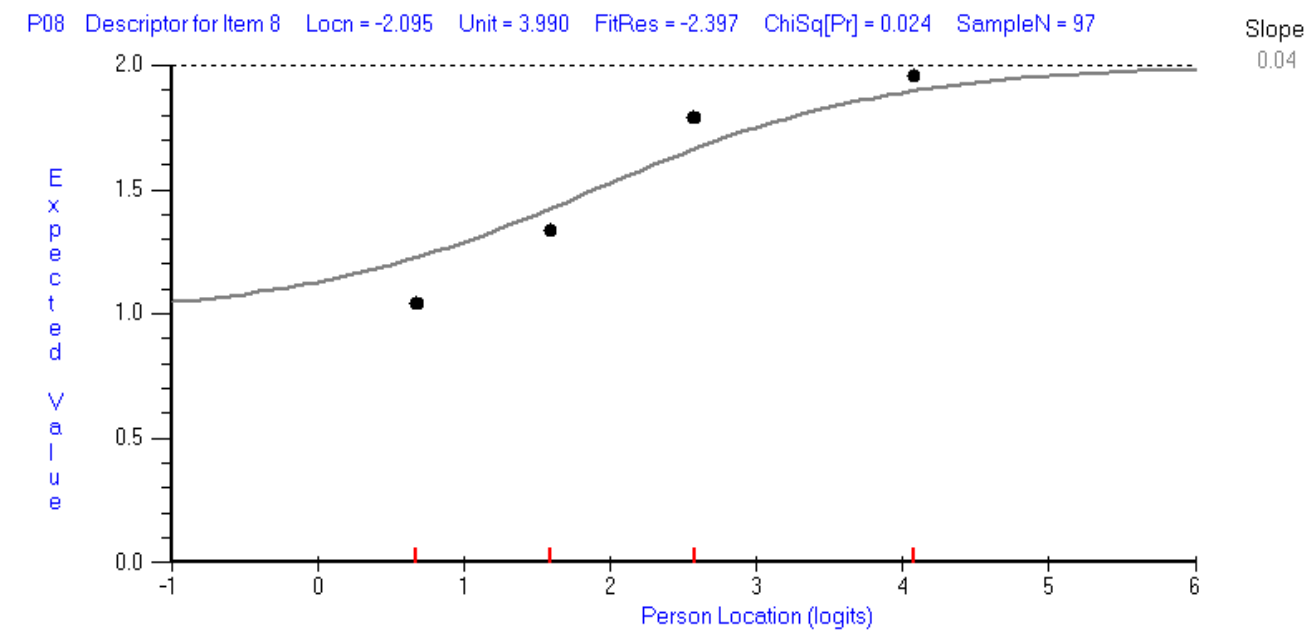

I am capable of making decisions related to my illness

Figure 1. ICC Capable of making decisions related to illness 
The psychometric properties of this scale were evaluated using the same criteria as the pilot scale. The order in which properties are examined may vary: here we used the order of procedures outlined by Andrich \& Styles.

\subsection{Analysis of Response Category Thresholds}

In principle, four response categories may provide greater precision of measurement than, say, a dichotomous (yes/no) response; however, this will be the case only if the categories are operating as expected, that is, with each successive category indicating more of the property - in this case, 'empowerment'. The cut-points (thresholds) between each successive pair of categories should be ordered. Thus Threshold 1 between categories "Strongly Disagree"/"Disagree" should occur lower on the scale continuum than Threshold 2 ("Disagree"/ "Agree"), which, in turn, should be located below Threshold 3 ("Agree"/“Strongly Agree"). Figure 2a shows the Category Characteristic Curves for an item with ordered categories. Five items (marked with asterisks in Table 2) were shown to have disordered thresholds, that is, categories were not ordered as required. An example of one of these items is shown in Figure $2 \mathrm{~b}$. When the categories for items with disordered thresholds were reduced to three by combining appropriate adjacent categories identified by the Category Probability Characteristic threshold curves in RUMM2020 (specifically the combining of the categories Strongly disagree and Disagree), the categories performed as required.

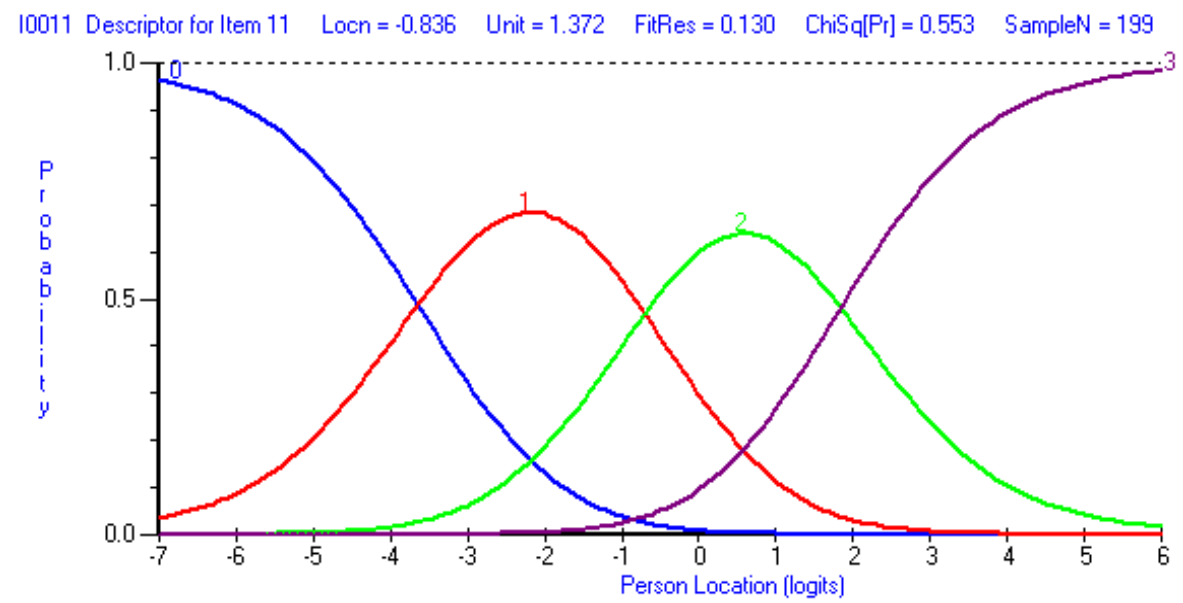

Item 11 - I still feel useful in my daily life

Figure 2(a). Category Probability Curves showing item with correctly ordered thresholds

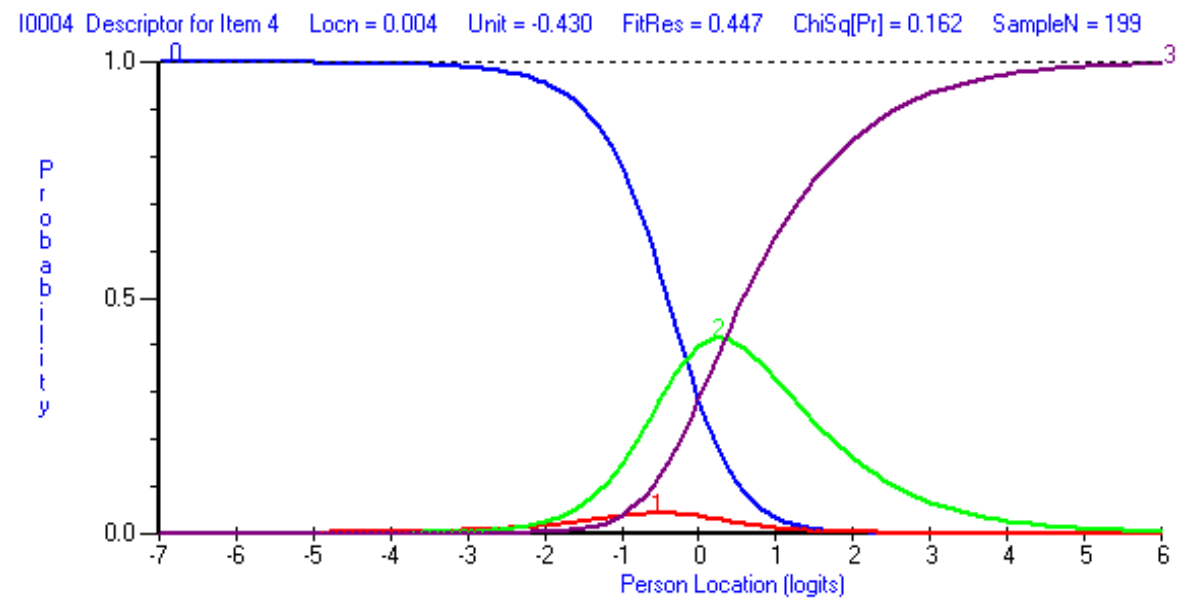

Item 4 - My family are very supportive

Figure 2(b). Category Probability Curves showing incorrectly ordered thresholds for Item 4 
Although it is strictly necessary to consider reducing the number of categories only for those items showing disordered thresholds, in practice, having different numbers of categories for different items in one scale is clumsy and likely to present problems for respondents. Hence a decision was taken to reduce the number of categories for all items, post hoc, to investigate whether this would eliminate the problem without reducing reliability. In this case, the Person Separation Index (a statistic reflecting reliability - equivalent to the Cronbach's Alpha in traditional test theory) was 0.783 before category reduction and 0.787 after reduction, supporting the decision to reduce the number of categories. Thus, unless the scale is to be used with people with a greatly diminished sense of empowerment (in which case they may differentiate Strongly Disagree and Disagree), it may be better to use three rather than four response categories in future analyses.

\subsection{Analysis of Item Fit to Model}

Table 5 shows the item fit and locations for the final PES.

Table 5. Chi Square tests of individual item fit (using reduced categories)

\begin{tabular}{|c|c|c|c|c|c|c|}
\hline Item (statement) & Location & SE & Fit Residual & Chi Sq & DF & Probability \\
\hline My family are very supportive. ${ }^{*}$ & -1.349 & 0.154 & 1.007 & 5.42 & 2 & 0.067 \\
\hline I need the support of my family and friends * & -1.184 & 0.206 & -0.01 & 0.36 & 2 & 0.835 \\
\hline My friends are always supportive. & -0.708 & 0.143 & 0.203 & 6.884 & 2 & 0.032 \\
\hline $\begin{array}{l}\text { I am capable of helping health professionals reach } \\
\text { decisions about my illness.* }\end{array}$ & -0.612 & 0.147 & -1.04 & 9.224 & 2 & 0.010 \\
\hline I am capable of handling my illness. & -0.594 & 0.146 & -1.533 & 7.747 & 2 & 0.021 \\
\hline $\begin{array}{l}\text { Health professionals are happy to include me in } \\
\text { decisions about my illness }\end{array}$ & -0.3 & 0.162 & -0.818 & 3.129 & 2 & 0.209 \\
\hline I still feel useful in my daily life. & -0.158 & 0.181 & 0.135 & 0.344 & 2 & 0.842 \\
\hline I can adapt to changes in my lifestyle. & 0.05 & 0.177 & -1.273 & 7.157 & 2 & 0.028 \\
\hline I have a lot of confidence in my local GP. & 0.392 & 0.125 & 1.814 & 8.759 & 2 & 0.013 \\
\hline My family and friends still rely on me.* & 0.5 & 0.186 & 0.637 & 3.146 & 2 & 0.207 \\
\hline I accept that I have to change my lifestyle.* & 0.531 & 0.141 & -0.231 & 4.867 & 2 & 0.088 \\
\hline My spiritual beliefs help me cope with my illness.* & 0.592 & 0.131 & 1.134 & 2.353 & 2 & 0.308 \\
\hline I have all the information I need to manage my illness. & 0.6 & 0.186 & -1.551 & 11.267 & 2 & 0.004 \\
\hline I want my family and friends to continue to rely on me. & 0.815 & 0.166 & 0.61 & 0.344 & 2 & 0.842 \\
\hline Complementary therapies help me cope with my illness. & 1.425 & 0.146 & 1.159 & 5.42 & 2 & 0.067 \\
\hline
\end{tabular}

We reiterate that no single test of fit is sufficient on which to base a decision about fit to the model. Rather, it is the picture that emerges from several sources of information is all important. Figure 3a shows the graphically represented item- trait interaction for an item with good fit, where the observed values across three step-intervals of person locations (the dots) follow the expected curve closely. 


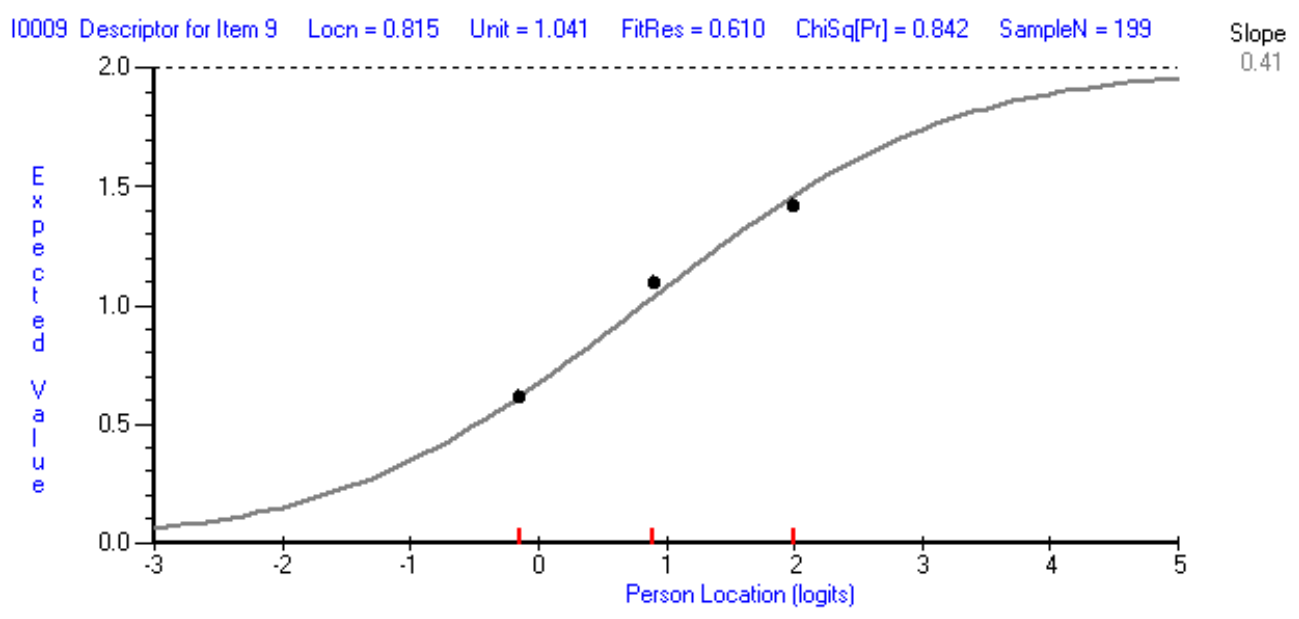

Item 9 - I want my family and friends to continue to rely on me

Figure 3(a). ICC Item trait interaction showing good fit

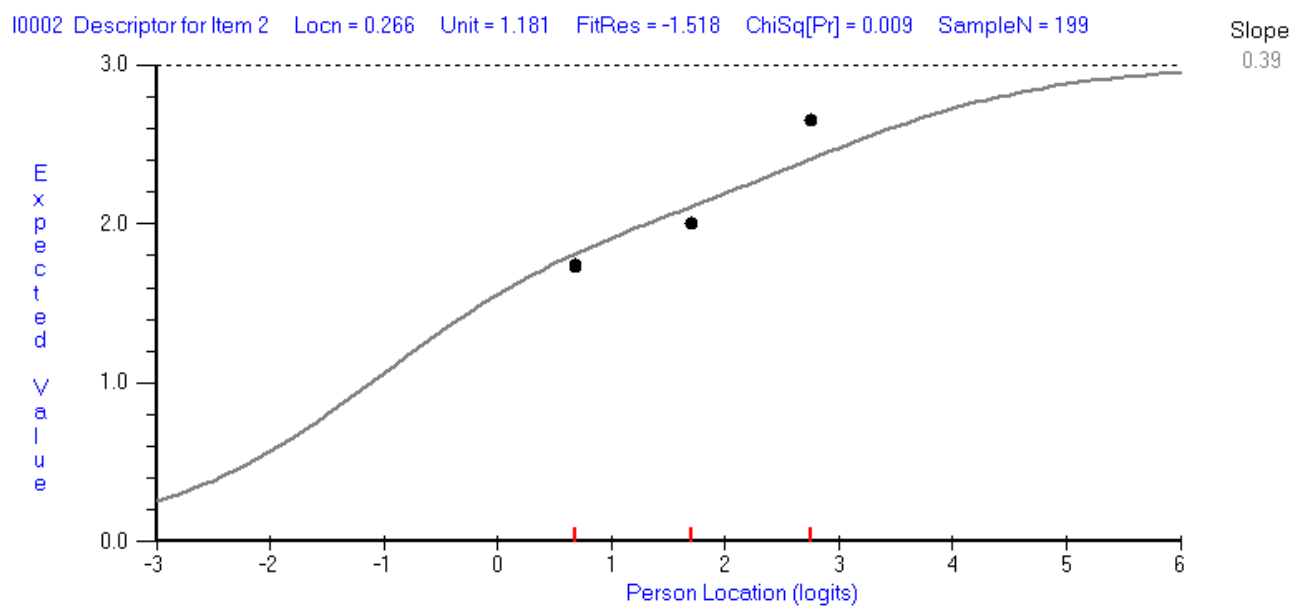

Item 8 - I have all the information I need to manage my illness

Figure 3(b). ICC Item trait interaction with least good fit

Two items showed some misfit on the item-trait interaction test of fit at the $p \leq 0.01$ level and a further four at $\mathrm{p} \leq 0.05$ level. However, the Bonferroni adjustment to the probabilities of the test of fit set the cut-off probability for significance at $p \leq 0.000667$. No items had a probability less than this value, thus no chi square statistic indicated misfit. Further, no log residual test of fit was $> \pm 2.0$ and the ICCs appeared acceptable. Figure $3 \mathrm{~b}$ shows that even the least well-fitting item is performing quite well. The item tends to over-discriminate between the middle and top scoring groups of people, but may be considered acceptable at this stage of scale development: the observed values for three step-intervals increase with increasing person locations and observed values are quite close to the theoretical curve.

Based on a consideration of the tests of fit and examination of the ICCs of items, we accepted that the 15 items form a single continuum at this level of scale. That is, all items are contributing to the measurement of a similar variable.

\subsection{Differential Item Functioning}

Three Site locations have been identified previously as haematology, oncology and radiation oncology. One item showed some DIF according to Site Location (Item 8 - Health professionals are happy to include me in decisions about my illness). The ICCs showed that persons at Sites 1 and 3 (haematology and breast clinic) tended to endorse this item more than persons at Site 2 (oncology), even though they had the same total scores. There was 
no significant DIF according to any other group factor. The conclusion is that the scale operates in a similar way across all groups. Item 8 could be examined in subsequent analyses when more data are available to check whether DIF continues to be evident.

\subsection{Item Dependencies}

Six pairs of items showed some item dependency at a residual correlation cut-point of 0.33 . No identifiable subset of items showed dependencies and analysis of principal component loadings from residual correlations confirmed there were no sub-scales.

\subsection{Distribution of Item Threshold and Person Locations and Reliability}

Although the graph of person and item-threshold location distributions presented in Figure 4 shows the person distribution to be skewed to the high end of the continuum (that is, generally persons responding were located towards the more empowered end of the scale), there is, nevertheless, a comparatively wider spread of person scores compared with the 28-item scale. This is evident when we compare it to Figure 5 from the initial pilot analyses. The mean person location of 1.063 logits $(\mathrm{sd}=1.276)$ indicates a relatively high level of empowerment amongst this sample of people. ANOVA showed no significant mean differences in levels of empowerment amongst groups of persons based on Site Location, Gender, Age or Marital Status (Significant group differences were not expected on the basis of these factors).

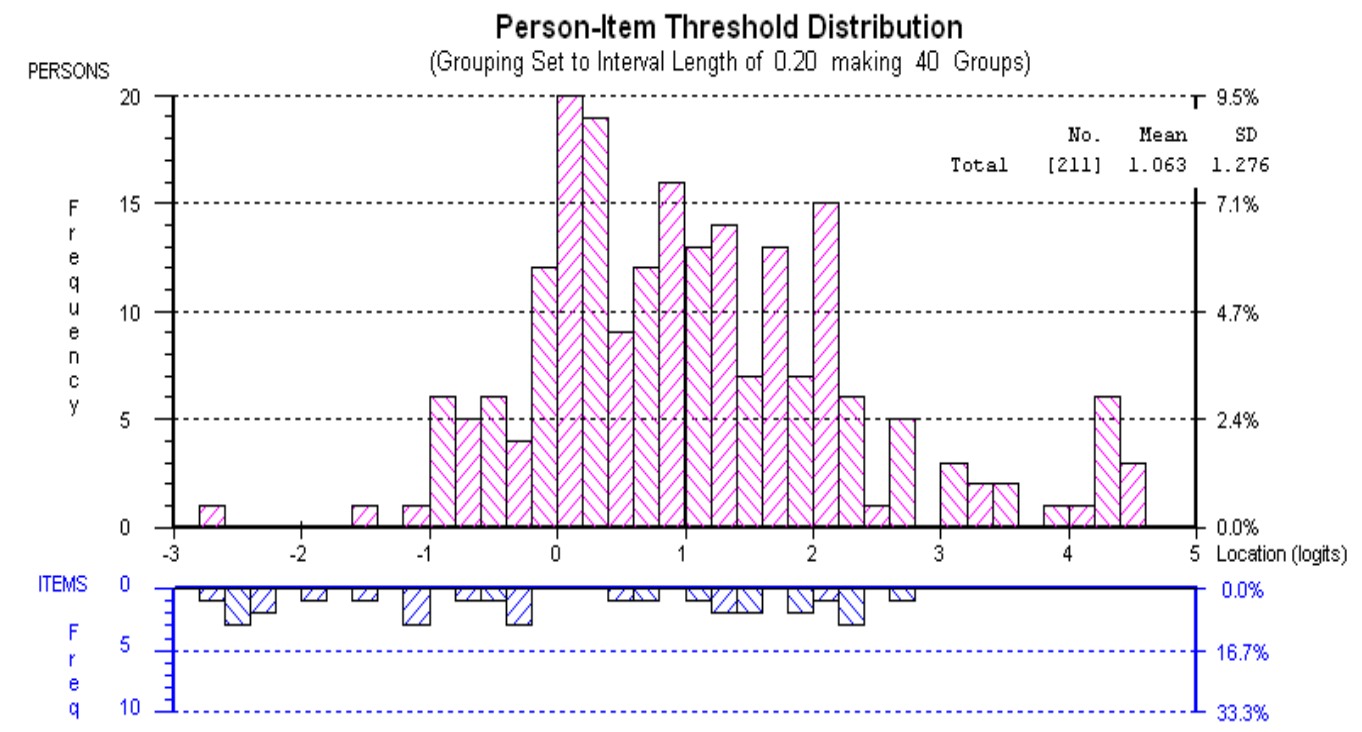

Figure 4. Distribution of Person-Item Threshold locations (final 15 item scale)

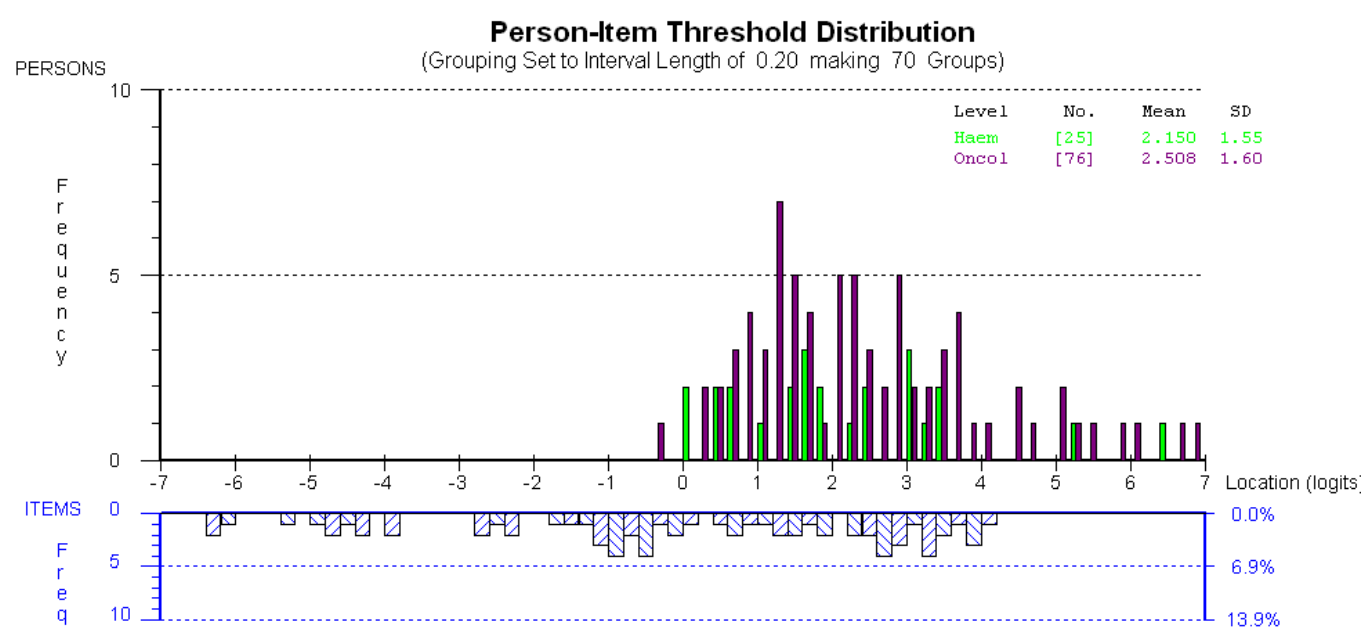

Figure 5. Distribution of Person-Item Threshold locations (original 28 item scale) 
The Person Separation Index of 0.78 is affected by the location of a number of persons beyond the highest item threshold (where there is no discrimination), but nevertheless indicates a satisfactory degree of reliability. The persons with the highest levels of empowerment are not being measured as reliably as the majority of people in this sample. That is, no items are targeted at their levels.

\section{Discussion}

Psycho-oncology emerged as a sub-specialty of oncology during the mid 1970s (Holland, 2002). The field today addresses two elements: the emotional and psychological responses of patients, and psychological, social and behavioral variables that impact on cancer morbidity and mortality (Holland, 2002; Carlson, Waller, \& Mitchell, 2012). There is increasing awareness of the importance of provision of psycho-oncology services to help patients adapt to their illness. The main aim of the PES was its use in busy clinical settings where a patient might complete it without assistance. The clinician would then add the patient's responses to obtain a raw score as an indicator of the level of empowerment for that person. Cut-off scores (still to be decided) for high, moderate and lower levels of empowerment would assist clinicians in assessing patients' ability to adapt to their illness and engage proactively with treatment. Clinicians could examine scores on individual items or subsets of items and use these to suggest strategies to help patients adapt to their illness. Since patients' positive attitudes towards support systems and resources impacts (Bulsara et al., 2004; Knott, Turnbull, Olver, \& Winefield, 2012) on their ability and motivation to gain a measure of control, it is useful for clinicians to be aware of levels of perceived empowerment in patients. This is in line with the general aim of psycho-oncological interventions to help patients develop and maintain a sense of control over the disease (Holland, 2002; Oh PJ \& Kim SH, 2010).

Perkins \& Zimmerman (1995) noted that empowerment research is focussed upon identifying strengths and enablers of optimal wellbeing rather than weaknesses and negative approaches to a problem. This study's qualitative data identified core strategies that may be used when patients seek access to support and resources, regardless of prognoses. Based on interview responses, it seems likely that levels of empowerment transcend specific points in time. Patients with high levels of empowerment achieve a level of control through adapting lifestyles and taking advantage of a range of supports. In spite of anxious times during the illness (Degner, 1998; Dyson et al., 2012; Merckaert et al., 2010), patients who spoke of being able to control the management of their treatment and illness side effects (Bulsara et al., 2004) felt more in control of the experience. Thus, empowerment impacts in a positive way on how patients react to setbacks (Patterson et al., 2002; Kyngas \& Rissanen, 2001).

Because our sample was smaller than that required for complete validation of the scale using the Rasch model, further validation with more diverse and larger samples of patients should be undertaken. However, results indicate the PES is capable of providing valid and reliable measures of levels of empowerment for most people in this study sample. The fact that some people with the highest locations on the continuum were not well-targetted using the current statements indicates more intense items could be developed. Finally, the Rasch analyses showed some difficulty amongst respondents in distinguishing between 'strongly disagree'/“disagree' for some statements - or the more extreme category was not appropriate for them. The reduction of categories from four to three for persons similar to those in this study would be beneficial without compromising reliability.

Analysis of data using the 15-item version of the PES and the larger sample indicated more variability in levels of patient empowerment than was the case with the pilot sample. Patients in the larger sample were more heterogeneous in regard to hospital location, treatment regimens and type of cancer - this may explain the increased variability of scores.

The fit of the PES to the Rasch model justifies the addition of raw scores to create a total empowerment score. Since the raw scores are linearly related to the transformed scores across most of the range of person locations, they could be used without the need to transform them using Rasch analysis. The Rasch logit scores do, however, provide more information than the raw scores at the two extremes of the continuum.

\section{Conclusion}

Analysis of the psychometric properties of the Patient Empowerment Scale has indicated its potential as a tool for clinicians in assessing and treating cancer patients. Analysis with the RUMM2020 program (Andrich et al., 2004) enabled the researchers to identify how the response categories were operating, how well items fitted the model, which items showed local dependence, and whether items were targetted to persons in this sample, as well as obtaining relative locations to enable comparisons amongst items and persons. Modifications to the scale on the basis of findings from the Rasch analysis resulted in shortening the scale from 28 to 15 items without loss of reliability. It is possible the PES could be used in the assessment of other patients since statements making up the PES provide generic markers for empowerment which are potentially relevant to a number of chronic 
illnesses. Certainly, as postulated, the use of the Rasch Model has shown that the concept of empowerment is a uniquely identifiable concept. In addition, the role of the PES as an outcome measure for future trials of interventions relating to patient empowerment is clear. The PES was developed to assess level of empowerment amongst patients. Although the PES will be useful for clinicians and researchers in future in assessing level of empowerment it is important to acknowledge the complexity of individualized empowerment as a concept. The role of the clinician is central to successfully motivating the patient through providing support and information related goals which are relevant to helping them cope with their illness. In the face of chronic illness such as cancer, patients need to be included in goal setting in regard to issues such as the management of the disease and where possible the type of treatment to be provided. The health professional (clinician or breast cancer nurse) can help to provide the patient with goal structures which are achievable and thus can encourage the patient to attempt 'goal achievable tasks' having identified areas of strength and limitation through the Patient Empowerment Scale.

\section{References}

Andrich, D. (1978). A rating formulation for ordered response categories. Psychometrika, 43, 561-73. http://dx.doi.org/10.1007/BF02293814

Andrich, D. (1988). Rasch Models for Measurement. Beverley Hills: Sage Publications.

Andrich, D. (2004). Controversy and the Rasch Model: A Characteristic of Incompatible Paradigms? Med Care, 42 (1 suppl).

Andrich, D., \& Styles, I. (2004). Final report on the psychometric analysis of the early childhood development instrument (EDI) using the Rasch Model: a technical paper commissioned for the development of the Australian Early Development Instrument (AEDI), Murdoch University.

Andrich, D., \& Styles, I. (2009). Will information in multiple choice items: a rationale based on the Rasch model. In Smith EV \& Stone GE (eds.). Criterion referenced testing: Practice analysis to score reporting using Rasch measurement models. Maple Grove, Minnesota: JAM Press.

Andrich, D., Sheridan, B., \& Guanzhong, L. (2004). Manual for Rumm2020: a software package for Rasch Measurement. Social Measurement Laboratory, Murdoch University, Perth, Western Australia.

Arora, N. K. (2003). Interacting with cancer patients: the significance of physicians' communication behavior. Social Science and Medicine, 57, 791-806. http://dx.doi.org/10.1016/S0277-9536(02)00449-5

Bond, T. G. \& Fox, C. M. (2001). Applying the Rasch Model: fundamental measurement in the human sciences. London: Lawrence Erlbaum Associates Publishers.

Bulsara, C., \& Styles, I. (2006) Empowering patients: coping with cancer. In Columbus AM (ed.). Advances in Psychology Research (pp 247-278), Nova Publishers US.

Bulsara, C., Chan, A., \& Styles, I. (2007). Motivating Women with Breast Cancer to achieve empowerment by the use of support strategies. In O’Neil, PW (ed.). Motivating Health Behaviour. Nova Publishers US.

Bulsara, C., Ward, A., \& Joske, D. (2004). Identifying Coping Strategies amongst Cancer Patients receiving Treatment for Haematological Malignancies. Journal of Clinical Nursing, 13, 251-258. http://dx.doi.org/10.1046/j.1365-2702.2003.00886.x

Carlson, L. E., Waller, A., \& Mitchell, A. J. (2012). Screening for distress and unmet needs in patients with cancer: review and recommendations. Journal of Clinical Oncology, 30, 1160-77. http://dx.doi.org/10.1200/JCO.2011.39.5509

Carver, C. S., Scheier, M. F., \& Weintraub, J. K. (1989). Assessing coping strategies: a theoretically based approach. Journal of Personality and Social Psychology, 56, 267-283. http://dx.doi.org/10.1037/0022-3514.56.2.267

Degner, L. (1998). Preferences to participate in treatment decision making: the adult model. Journal of Pediatric Oncology Nursing, 3(suppl), 3-9. http://dx.doi.org/10.1016/S1043-4542(98)90069-8

Dyson, G. J., Thompson, K., Palmer, S., Thomas, D. M., \& Schofield, P. (2012). The relationship between unmet needs and distress amongst young people with cancer. Supportive Care in Cancer, 20, 75-85. http://dx.doi.org/10.1007/s00520-010-1059-7

Golant, M., Altman, T., \& Martin, C. (2003). Managing cancer side effects to improve quality of life: a cancer $\begin{array}{lllll}\text { psycho-education } & \text { program. } & \text { Cancer } & \text { Nursing, } & \text { 26, }\end{array}$ http://dx.doi.org/10.1097/00002820-200302000-00005 
Hagquist, C. (2001). Evaluating composite health measures using Rasch Modelling. Social and Preventative Medicine, 46, 369-378. http://dx.doi.org/10.1007/BF01321663

Holland, J. C. (2002). History of psycho-oncology: overcoming attitudinal and conceptual barriers. Psychosomatic Medicine, 64, 206-221.

Knott, V., Turnbull, D., Olver, I., \& Winefield, A. (2012). A grounded theory approach to understand the cancer-coping process. British Journal of Health Psychology, 17, 551. http://dx.doi.org/10.1111/j.2044-8287.2011.02054.x

Kyngas, H., \& Rissanen, M. (2001). Support as a crucial predictor of good compliance of adolescents with a chronic disease. Journal of Clinical Nursing, 10, 767. http://dx.doi.org/10.1046/j.1365-2702.2001.00538.x

Little, M., Jordens, C. F. C., Paul, K., Montgomery, K., \& Philipson, B. (1998). Liminality: a major category of the experience of cancer illness. Social Science and Medicine, 47, 1485-1894. http://dx.doi.org/10.1016/S0277-9536(98)00248-2

Merckaert, I., Libert, Y., Messin, S., Milani, M., Slachmuylder, J. L., \& Razavi, D. (2010) Cancer patients' desire for psychological support: prevalence and implications for screening patients' psychological needs. Psycho-Oncology, 19, 141-9. http://dx.doi.org/10.1002/pon.1568

Molinari, C., Ahern M., \& Hendryx, M. (1998). The relationship of community quality to the health of women and men. Social Science and Medicine, 47, 1113-1120. http://dx.doi.org/10.1016/S0277-9536(98)00114-2

Oh, P. J., \& Kim, S. H. (2010) Effects of a brief psychosocial intervention in patients with cancer receiving adjuvant therapy. Oncology Nursing Forum, 37, E98-104. http://dx.doi.org/10.1188/10.ONF.E98-E104

Patterson, R. E., Neuhouser, M. L., Hedderson, M. M., Schwartz, S. M., Standish, L. J., Bowen, D. J., \& Marshall, L. M. (2002). Types of alternative medicine used by patients with breast, colon, or prostate cancer: predictors, motives, and costs. Journal of Alternative and Complementary Medicine, 8, 477-485. http://dx.doi.org/10.1089/107555302760253676

Perkins, D., \& Zimmerman, M. A. (1995). Empowerment theory, research and application. American Journal of Community Psychology, 23, 569- 579. http://dx.doi.org/10.1007/BF02506982

Rasch, G. (1980). Foreword and introduction. Probabilistic Models for some intelligence and attainment tests. Ix-xix. Chicago: University of Chicago Press.

Rissel, C. (1994). Empowerment: The holy grail of health promotion? Health Promotion International, 6, 197-205.

Ryan, J. P. (1983). Introduction to Latent Trait Analysis and Item Response Theory. In Hathaway (Ed.). Testing in Schools. New directions for testing and measurement. San Francisco: Jossey-Bass.

Taylor, S. E., Litcheman, R. R., \& Wood, J. V. (1984). Attributions, beliefs about control and adjustment to breast cancer. Journal of Personality and Social Psychology, 46, 489-502. http://dx.doi.org/10.1037/0022-3514.46.3.489

Triandis, H. C. (1971). Attitude and Attitude Change. John Wiley \& Sons Inc.

Ward, A., Hardwick, K., \&Joske, D. J. (2000). The Evaluation of the Haematology Shared Care Pilot Project WA, Department of General Practice, University of Western Australia.

Watson, M., Greer, S., Young, J., Inayat, Q., Burgess, C., \& Robertson, B. (1998). Development of a questionnaire measure of adjustment to cancer: the MAC scale. Psychological Medicine, 18, 203-209. http://dx.doi.org/10.1017/S0033291700002026

Wright, B., \& Stone, M. (1979). Best test design. Chicago: MESA Press.

Wu, L. M., Chin, C. C., Haase, J. E., \& Chen, C. H. (2009). Coping experiences of adolescents with cancer: a qualitative study. Journal of Advanced Nursing, 65, 2358-66. http://dx.doi.org/10.1111/j.1365-2648.2009.05097.x

Zaza, C., Sellick, S. M., \& Hillier, L. M. (2005). Coping with cancer: what do patients do? Journal of Psychosocial Oncology, 23, 55-71. http://dx.doi.org/10.1300/J077v23n01_04

Zigmond, A., \& Snaith, R. P. (1983).The Hospital Anxiety and Depression Scale. Acta Psychiatrica Scandinavica, 67, 361-370. http://dx.doi.org/10.1111/j.1600-0447.1983.tb09716.x 